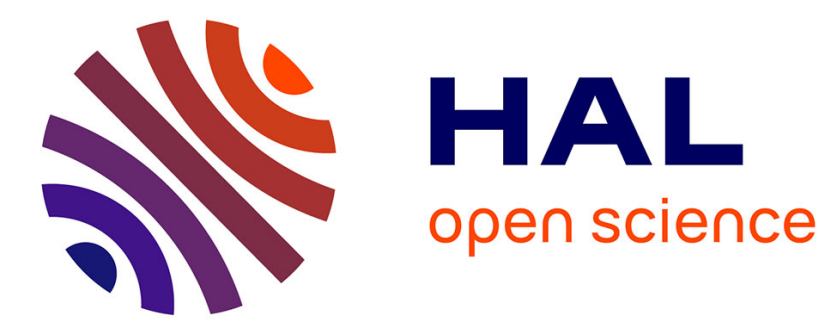

\title{
Advances in editing microalgae genomes
}

Fayza Daboussi

\section{To cite this version:}

Fayza Daboussi. Advances in editing microalgae genomes. Perspectives in Phycology, 2017, 4 (1), pp.17-23. 10.1127/pip/2017/0071 . hal-01606205

\section{HAL Id: hal-01606205 \\ https://hal.science/hal-01606205}

Submitted on 26 May 2020

HAL is a multi-disciplinary open access archive for the deposit and dissemination of scientific research documents, whether they are published or not. The documents may come from teaching and research institutions in France or abroad, or from public or private research centers.
L'archive ouverte pluridisciplinaire HAL, est destinée au dépôt et à la diffusion de documents scientifiques de niveau recherche, publiés ou non, émanant des établissements d'enseignement et de recherche français ou étrangers, des laboratoires publics ou privés.

\section{다(1) (2)}

Distributed under a Creative Commons Attribution - ShareAlikel 4.0 International 


\title{
Advances in editing microalgae genomes
}

\section{Fayza Daboussi}

Laboratoire d'Ingénierie des Systèmes Biologiques et Procédés, Université de Toulouse, CNRS, INRA, INSA Toulouse France; fayza.daboussi@insa-toulouse.fr

\section{With 2 figures}

\begin{abstract}
There have been significant advances in microalgal genomics over the last decade. Nevertheless, there are still insufficient tools for the manipulation of microalgae genomes and the development of microalgae as industrial biofactories. Several research groups have recently contributed to progress by demonstrating that particular nucleases can be used for targeted and stable modifications of the genomes of some microalgae species. The nucleases include Meganucleases, Zinc Finger nucleases, TALE nucleases and, as shown most recently, the CRISPR/Cas9 system. These molecular editing tools allow gene knock-out and gene knock-in manipulations and the introduction of enzyme variants; they will facilitate the study of microalgae and in particular gene function and, thereby favoring exploitation of the metabolic potential of microalgae.
\end{abstract}

Keywords: Microalgae, biotechnology, targeted genome modifications, engineered nucleases, TALENs, CRISPR/CAS9 system

\section{Microalgae, the rough diamond of biotechnology}

Microalgae have enormous potential as cell factories: like plants properties, they can produce complex molecules using $\mathrm{CO}_{2}$ as a substrate; like microorganisms, they grow rapidly; and they produce a wide variety of bioproducts (proteins, carbohydrates, lipids and pigments). Consequently, they are the rough diamonds of biotechnology (Barra et al. 2014). Microalgae also have potential as expression systems for medically useful proteins and as edible vaccines (Specht et al. 2010). Against the background of the exhaustion of fossil fuels and efforts to decrease greenhouse gas emissions, microalgae have emerged as promising biocatalysts for the sustainable production of chemicals and biofuels, because they can accumulate and store energy-rich compounds, such as triacylglycerol and carbohydrates (Alonso et al. 2000). Nevertheless, a number of barriers need to be overcome before profitable commercialisation of microalgae in the chemical and biofuel markets.

\section{Traditional techniques to improve performance and yield}

For several years, there have been efforts to develop the metabolic potential of microalgae. Various techniques are available for enhancing cell growth and/or the accumulation of bioproducts. Oceanographic campaigns have been conducted to explore biodiversity and discover new species with particular properties. In parallel, there has been work to optimise cultivation conditions to enrich microalgae in specific compounds. Nutrient deprivation has been successfully used to boost lipid content, although generally at the expense of biomass productivity (Hu et al. 2008, Breuer et al. 2012). Physical and chemical mutagens have been used to modify the genetic heritage, and efficient, rapid and robust high-throughput screening- methodologies have been employed with the aims of circumventing dependence on stress and to decrease cultivation-related costs (Huesemann et al. 2009, Beacham et al. 2015). This strategy is attractive, but the control of genome modifications is still limited impeding research into microalgae metabolism, a prerequisite for metabolic engineering.

\section{From classical genetic tools to targeted genome editing}

The development of new and affordable methods for wholegenome sequencing, and the availability of techniques allowing transformation of more than 50 microalgae species facilitate analysis of gene function. Techniques now used are based on random insertional mutagenesis followed by phenotypic selection (Galván et al. 2007) or on modulation of gene expression by overexpression or silencing targeted genes using RNA interference (Schroda et al. 1999, Schroda 2006, Doron et al. 2016) or microRNA (Molnár et al. 2007, Zhao et al. 2009, Cerutti et al. 2011, Doron et al. 2016). 
These methodologies have provided knowledge about the metabolism and physiology of microalgae (Cerutti et al. 2011, Doron et al. 2016). They are nevertheless limited for the creation of industrially useful strains: RNA interference often only incompletely repressed gene expression; the longterm stability of the epigenetic repression is uncertain; and the deletion or introduction of mutations in relevant target genes is unlikely with random processes.

In contrast, the targeted insertion of a DNA sequence via homologous recombination (HR) circumvents these limitations to a large extent. This process is very efficient and common in cyanobacteria and the chloroplast genome of some microalgae (Matsuoka et al. 2001, Marín-Navarro et al. 2007), but is much less effective for modifying the nuclear genome in microalgae. Targeted nuclear genome modification based on HR is currently restricted to three microalgae species: Cyanidioschizon merolae (Minoda et al. 2004), Nannochloropsis sp. (Kilian et al. 2011) and Ostreococcus tauri (Lozano et al. 2014). For all other species, including the model species $P$. tricornutum and $C$. reinhardtii, the efficiency of HR is extremely low $\left(<10^{-6}\right)$.

As described for plants (Puchta et al. 1993), yeast (Plessis et al. 1992, Choulika et al. 1995) and mammalian cells (Rouet et al. 1994), the introduction of a double-strand break (DSB), by the homing endonuclease I-SceI, significantly increases HR-frequencies 1000-fold. Consequently, enzymes able to recognize and introduce a DSB in a sitespecific sequence have been designed. There are two main mechanisms for repairing DSB (Fig. 1): non-homologous end joining (NHEJ), in which the broken chromosomes are re-joined more or less accurately, often with small deletions and insertions (Takata et al. 1998); and homologous recombination (HR), in which DNA templates bearing sequence similarity to the break site are used resulting in sequence changes to the target locus. NHEJ seems to be the main DSB repair mechanism in plants, mammalian cells and probably in microalgae (with the exception of Cyanidioschizon merolae, Nannochloropsis sp and Ostreococcus tauri). Very little is known about these processes in microalgae due to the difficulties of assigning a function to a gene. Most current knowledge is from the analysis of a few $C$. reinhardtii DSB-repair mutants obtained by physical and/or chemical mutagenesis (Vlcek et al. 2008, Plecenikova et al. 2014) and not even the key genes have been identified. Even so, a race is underway to develop molecular scissors able to modify the genome of microalgae species.

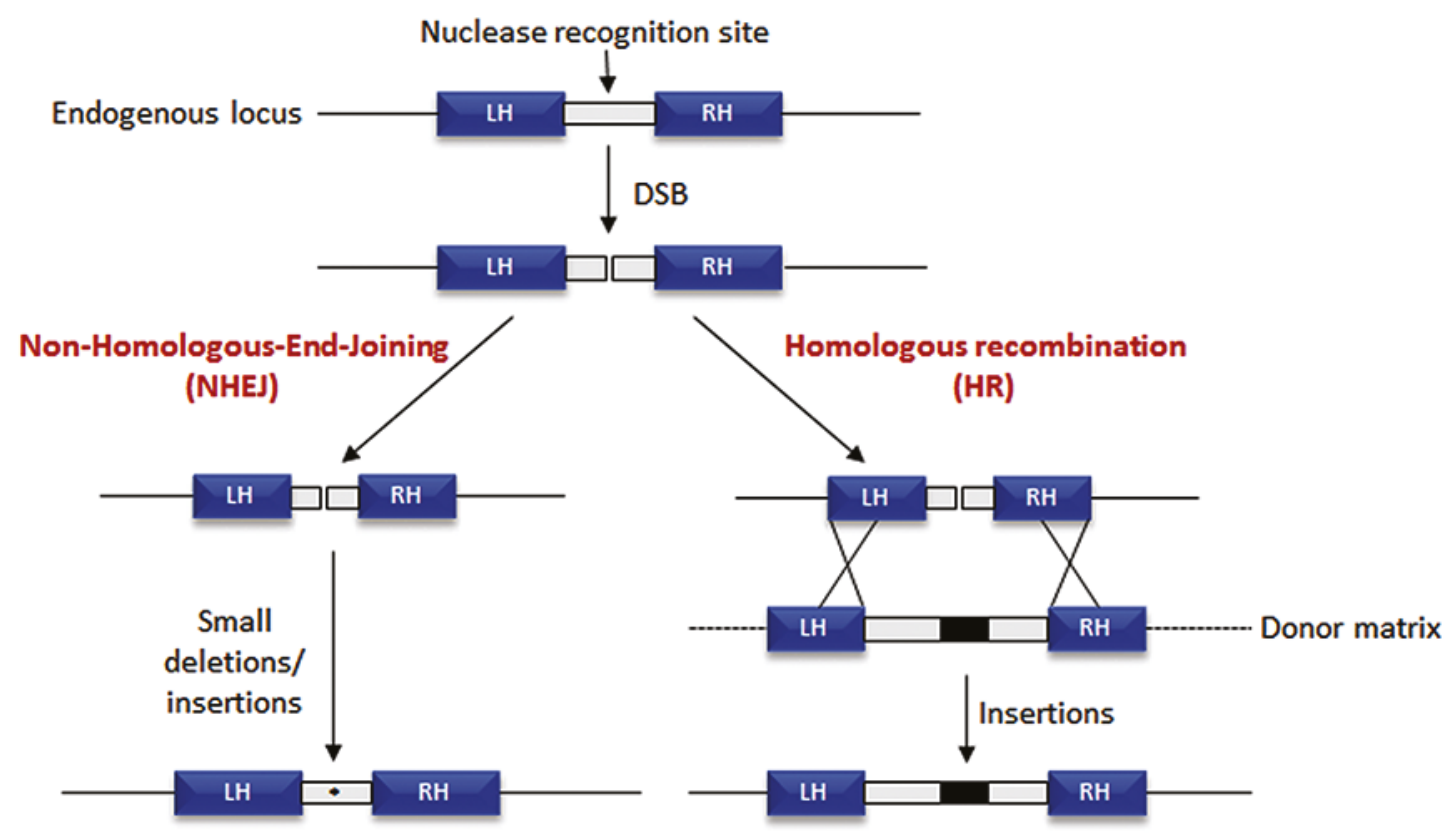

Applications: Gene inactivation

Gene insertion/ Gene modification/ Gene tagging/ Gene inactivation

Fig. 1. Overview of in-vivo double-strand break repair mechanisms by non-homologous-end-joining (NHEJ) and homologous recombination (HR) and how they can be exploited to generate genetic modifications; the result in these examples is disruption of the nuclease target site and repair either by targeted mutagenesis $\left(^{*}\right)$ or targeted gene insertion (black rectangle). For targeted gene insertion, the donor matrix consists of two homologous regions ( $\mathrm{LH}$, left homology; $\mathrm{RH}$, right homology) flanking a sequence to be inserted. This process enables the integrated DNA to (i) express one or several genes, (ii) inactivate specific genes, (iii) produce a protein marker (i.e. fluorescent protein) fused to a protein of interest (gene tagging) and (iv) replace a gene in a targeted manner or introduce single-nucleotide substitutions (for gene correction or to generate enzyme variants). 


\section{Designed nucleases, powerful tools to study gene function and to generate novel crops}

Custom molecular scissors would allow modification of the genome in a site-specific manner, and thus facilitate basic and applied research. Using such tools, it would be possible to knock out and knock in targeted genes for gene inactivation, gene insertion, and gene replacement or to introduce specific mutations into genes. Gene function could then be studied, and foreign genes introduced into cells (Fig. 1). Here, we will focus on the four classes of sequence-specific nucleases (MNs, ZFNs, TALENs, CRISPR/Cas9) (Fig. 2) successfully used to modify the genome of microalgae species. All of them were derived from natural molecules, whose functions have been adapted to create powerful tools for genome engineering.

Meganucleases are designed sequence-specific endonucleases that recognise and cleave long DNA sequences (1830 base pairs) generating DSBs (Silva et al. 2011). They are derived from homing endonucleases, which are involved in the lateral transfer of introns or inteins (Bell-Pedersen et al. 1990, Jacquier \& Dujon 1985, Kostriken et al. 1983). Unlike other classes of nucleases, the meganuclease template con- tains both the recognition and cleavage functions in the same scaffold. By introducing a small number of variations into the amino acid sequence in the DNA-binding domain of those proteins and then selecting functional proteins with variations of the natural recognition site, it is possible to generate customised meganucleases with a great range of target sites (Chevalier et al. 2002, Epinat et al. 2003, Silva et al. 2006, Daboussi et al. 2015). Further scaffold optimisations have improved nuclease activity and specificity (Smith et al. 2006, Grizot et al. 2009, Daboussi et al. 2012, Delacôte et al. 2013, Boissel et al. 2014). The first proof of concept of targeted genome editing in microalgae was by my group in the Cellectis Company (Duchateau et al. 2013, Daboussi et al. 2014, Duchateau et al. 2014). High frequencies of both targeted mutagenesis and targeted gene insertion have been achieved in diatoms using two engineered meganucleases. However, the production of such molecular scissors is too time-consuming and not sufficiently flexible compared to TALEN and CRISPR/Cas9 systems, to envision a significant role in microalgae genome engineering.

Zinc Finger Nucleases are chimeric proteins composed of zinc finger DNA-binding domains fused to the non-specific type II restriction enzyme FokI. Each DNA-binding domain
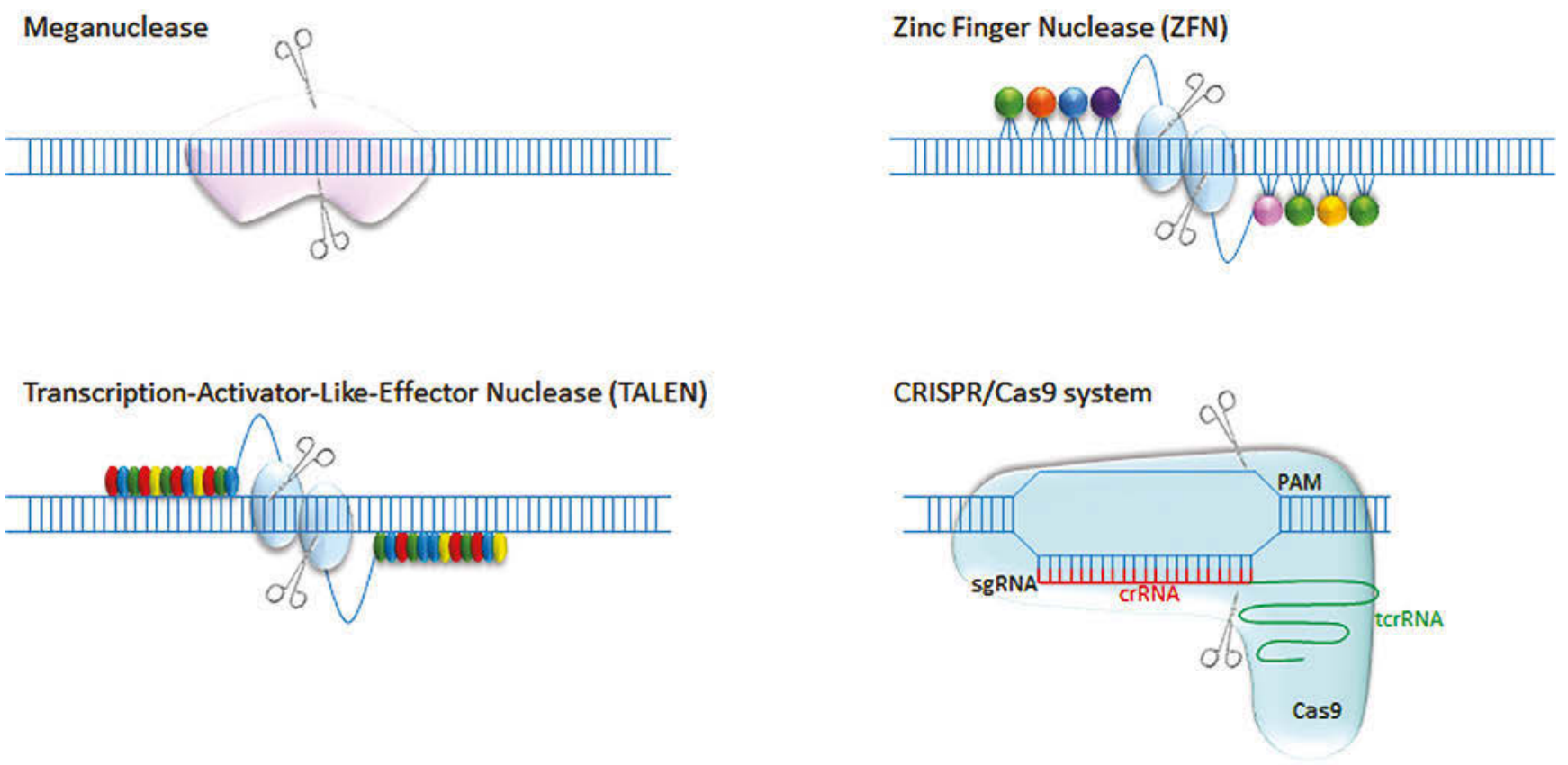

Fig. 2. Molecular scissors for causing double-strand break (a) Meganucleases derived from homing endonucleases such as dimeric meganuclease I-Crel recognise a 21-nucleotide binding site. The DNA-binding domain of I-Crel was modified to recognize specific target sequences, (b) Zinc finger nuclease composed of a DNA-binding domain of three to four zinc fingers, each zinc finger recognizing three nucleotides, resulting in recognition of a 9 to 12-nucleotide-long DNA sequence. Each DNA-binding domain is fused to the Fokl nuclease domain. A heterodimeric enzyme. (c) Transcription activator-like effector nucleases (TALENs): the DNA-binding domain consists of 14-24 module repeats of 33 to 35 amino acids whose two polymorphic amino acids are responsible for the specific recognition of one nucleotide. (d) RNA-guided endonuclease CRISPR/Cas9, where a chimeric single-guide RNA (sgRNA) corresponding to 20 nucleotides of a protospacer-adjacent motif (PAM: NGGs responsible in the case of $S$. pyogenes Cas9) is responsible for the specificity of the Cas9 nuclease, containing two Ruv $\mathrm{C}$ and $\mathrm{HNH}$ nuclease domains. 
is composed of three to four binding arrays from transcription factors (each one recognising a three nucleotide DNA sequence). The DNA-binding domain of each monomer of the ZFN enzyme therefore recognises a 9-12 nucleotide sequence in genomic sequence. The FokI cleavage domain functions enzymatically as a dimer, thus two DNA binding domains are required to form a dimer for activity (Kim et al. 1996, Smith et al. 2000). Using ZFN, Sizova and collaborators modified the sequence of the $C O P 3$ gene (encoding the light-activated ion channel channelrhodopsin-1) in C. reinhardtii via both targeted NHEJ-induced-mutagenesis and targeted mutagenesis induced by homologous recombination (Sizova et al. 2013). Despite efforts at optimisation, ZFN are still labour-intensive and lack specificity (Gabriel et al. 2011), leading scientists to favour the new methodologies described below.

TALENs have architecture similar to ZFNs because the DNA-binding domain is also fused to the non-specific catalytic head FokI (Christian et al. 2010). The DNA-binding domain of TALENs is derived from TALE (Transcriptional Activator-Like Effectors), proteins produced by a plant bacterial pathogen belonging to the genus Xanthomonas. These proteins activate the transcription of a specific plant gene to promote bacterial infection (Bogdanove et al. 2010). The DNA-binding domain comprises an array of typically 14-24 repeat units of approximately 33 to 35 amino acids, nearly identical to one another, except for two polymorphic amino acids called RVDs (repeat variable di-residue) located at positions 12 and 13, responsible for the specific recognition of a particular nucleotide. There is preferential pairing between $\mathrm{A}, \mathrm{C}, \mathrm{G}, \mathrm{T}$ nucleotides and the repeat modules harbouring respectively NI, HD, NN, and NG RVDs (Boch et al. 2009, Moscou \& Bogdanove 2009). Based on this specificity, it is straightforward to generate engineered TALE DNA-binding domains (like LEGO ${ }^{\circledR}$ blocks), and fuse them to nuclease $(\mathrm{N})$ domains. The TALEN-mediated genome modification has been reported for the diatom Phaeodactylum tricornutum for both studying gene function (Weyman et al. 2014, Fortunato et al. 2016) and generating crops with industrial potential (Duchateau et al. 2013, Duchateau et al. 2014, Daboussi et al. 2014). The proof of concept of TALEN-induced genetic modification in microalgae was established in 2013 by demonstrating a high frequency of targeted mutagenesis resulting from targeting seven different endogenous loci. The potential of these molecular editing tools for metabolic engineering was illustrated by the creation of a high-lipid-producing strain by inactivating of a gene key for energy storage in the form of sugars (Daboussi et al. 2014). Several research groups have exploited this TALEN-genome editing strategy for studying gene function, in experiments involving the inactivation of the red/far-red light-sensing phytochrome $(D P H)$ via NHEJ (Fortunato et al. 2016), and the disruption of the urease via HR (Weyman et al. 2014).
The CRISPR/Cas9 (Clustered Regularly Interspaced Short Palindromic Repeats) system is based on an RNAguided DNA cleavage defence system, present in bacteria and archaea. This system confers an "acquired immunity" against bacteriophages by storing the foreign DNA in their genome memory at the CRISPR locus. The molecular mechanism governing the accurate positioning of the double-strand breaks in DNA in the natural CRISPR/Cas9 system has been described (Deltcheva et al. 2011), and then engineered to produce targeted DSBs at specific targeted sites (Jinek et al. 2012). The CRISPR/Cas9 system has been developed into a simple toolkit based on a custom single guide RNA (sgRNA) that contains a targeting sequence (crRNA sequence) and a cas9 nuclease-recruiting sequence (tracrRNA). The crRNA region includes nucleotides homologous to the genomic target to be modified. The binding specificity is based on the gRNA and a 3-nucleotide sequence downstream called the protospacer adjacent motif (PAM; NGG, in the case of S. pyogenes Cas9). The Cas9 nuclease carries two nuclease domains (HNH and RvuC) and cleaves both DNA strands generating DSBs at sites defined by the 20-nucleotide guide sequence. There are three main reasons why CRISPR/ Cas9 has contributed to making genome engineering straightforward: first, it is simple, due to the complementarity of the RNA guide with the target DNA; second, the simultaneous use of several RNA guides, each targeting a different sequence, allows multiple genetic modifications simultaneously; and third, it is cheap, and a few dozen Euros are sufficient to obtain scissors that can be used by scientists around the world for genome editing (see for a review Hsu et al. 2014).

The first demonstration of targeted genome modification by CRISPR/Cas9 technology in microalgae was in C. reinhardtii but cellular toxicity hampered the generation of genome-modified strains (Jiang et al. 2014). More than two years were required to develop efficient Cas9 strategies that did not affect cell growth, in first $P$. tricornutum by inactivating the CPSRP54 gene encoding the chloroplast signal recognition particle 54 (Nymark et al. 2016) and then in C. reinhardtii. Both targeted mutagenesis and targeted homologous recombination induced by the CRISPR/Cas9 system have been obtained in $C$. reinhardtii by targeting three genes: MAA7 that encodes the beta subunit of tryptophan synthase (TSB); the antennal assembly gene CpSRP43 that encodes chloroplast SRP43; and the chlorophyll biosynthetic gene ChlM that encodes Mg-protoporphyrin IX S-adenosyl methionine O-methyl transferase. A novel strategy was used to avoid cytotoxicity: Cas9 ribonucleoproteins were provided and the Cas9 protein and sgRNAs were combined (Baek et al. 2016, Shin et al. 2016). This technology will undoubtedly be adapted to other microalgae species as indicated by recent work with the diatom Thalassiosira pseudonana (Hopes et al. 2016) and the industrial oleaginous microalga Nannochloropsis oceanica (Wang et al. 2016). 


\section{Conclusion and perspectives}

Genome engineering can be considered to have been subject to a revolution rather than having seen significant progress. Genome editing tools now available allow efficient and specific modification of the genome of microalgae species, facilitating diverse investigations. This is just the beginning and scientists are racing to develop new genome editing tools and adapt them to other microalgae species. The specificity of CRISPR/Cas9 system has been widely debated over the past year. Indeed, mismatches are tolerated in the $5^{\prime}$-end region of sgRNA, thereby reducing Cas9 specificity to less than $15 \mathrm{bp}$, which is much lower than that of meganucleases, ZFNs and TALENs. Although there has been extensive work on this issue in bacteria, mammals and plants, the extent of off-site activity is still not completely clear. To overcome this potential drawback, software tools have been created to identify potential off-target sites in silico and select the most specific target sites. In addition, new engineerable scaffolds have been developed to improve specificity (Ran et al. 2013, Guilinger et al. 2014, Tsai et al. 2014). Progress made in improving the specificity of these designed nuclease-based technologies and in optimising these tools should help with modifying the microalgae genome more predictably.

To create new tools for the control of gene expression, the TALE DNA-targeting domain and the catalytically inactive Cas9 have been fused to a variety of other functional domains. Several functional fusions have been reported with activator, repressor, DNA and histone methylase domains. These fusions can form hybrid proteins that function as sitespecific transcription activators, transcription repressors or epigenetic modifiers (Gao, X. et al. 2014). The adaptation of these promising approaches to microalgae (as already done by Gao, H. et al. 2014 in C. reinhardtii) will provide powerful tools. This will in turn allow a better understanding of gene expression and both the manipulation of endogenous regulatory networks and creation synthetic gene circuits, which is the basis of synthetic biology.

\section{References}

Alonso, D.L., Belarbi, E.H., Fernández-Sevilla, J.M., RodríguezRuiz, J. \& Molina Grima, E. (2000): Acyl lipid composition variation related to culture age and nitrogen concentration in continuous culture of the microalga Phaeodactylum tricornutum. - Phytochemistry 54: 461-471.

Baek, K., Kim, D.H., Jeong, J., Sim, S.J., Melis, A., Kim, J.-S., Jin, E. \& Bae, S. (2016): DNA-free two-gene knockout in Chlamydomonas reinhardtii via CRISPR-Cas9 ribonucleoproteins. - Sci. Rep. 6: 30620.

Barra, L., Chandrasekaran, R., Corato, F. \& Brunet, C. (2014): The challenge of ecophysiological biodiversity for biotechnological applications of marine microalgae. - Mar. Drugs 12: 1641-1675.
Beacham, T.A., Macia, V.M., Rooks, P., White, D.A. \& Ali, S.T. (2015): Altered lipid accumulation in Nannochloropsis salina CCAP849/3 following EMS and UV induced mutagenesis. Biotechnol. Rep. 7: 87-94.

Bell-Pedersen, D., Quirk S., Clyman J. \& Belfort, M. (1990): Intron mobility in phage T4 is dependent upon a distinctive class of endonucleases and independent of DNA sequences encoding the intron core: mechanistic and evolutionary implications. Nucleic Acids Res. 18: 3763-3770.

Boch, J., Scholze, H., Schornack, S., Landgraf, A., Hahn, S., Kay, S., Lahaye, T., Nickstadt, A. \& Bonas, U. (2009): Breaking the code of DNA binding specificity of TAL-type III effectors. Science 326: 1509-1512.

Bogdanove, A.J., Schornack, S. \& Lahaye, T. (2010): TAL effectors: finding plant genes for disease and defense. - Curr. Opin. Plant Biol. 13: 394-401.

Boissel, S., Jarjour, J., Astrakhan, A., Adey, A., Gouble, A., Duchateau, P., Shendure, J., Stoddard, B.L., Certo, M.T., Baker, D. \& Scharenberg, A.M. (2014): megaTALs: a rare-cleaving nuclease architecture for therapeutic genome engineering. Nucleic Acids Res. 42: 2591-2601.

Breuer, G., Lamers, P.P., Martens, D.E., Draaisma, R.B. \& Wijffels, R.H. (2012): The impact of nitrogen starvation on the dynamics of triacylglycerol accumulation in nine microalgae strains. Bioresour. Technol. 124: 217-226.

Cerutti, H., Ma, X., Msanne, J. \& Repas, T. (2011): RNA-Mediated Silencing in Algae: Biological Roles and Tools for Analysis of Gene Function. - Eukaryot. Cell 10: 1164-1172.

Chevalier, B.S., Kortemme, T., Chadsey, M.S., Baker, D., Monnat, R.J. \& Stoddard, B.L. (2002): Design, Activity, and Structure of a Highly Specific Artificial Endonuclease. - Mol. Cell 10: 895-905.

Choulika, A., Perrin, A., Dujon, B. \& Nicolas, J.F. (1995): Induction of homologous recombination in mammalian chromosomes by using the I-SceI system of Saccharomyces cerevisiae. - Mol. Cell. Biol. 15: 1968-1973.

Christian, M., Cermak, T., Doyle, E.L., Schmidt, C., Zhang, F., Hummel, A., Bogdanove, A. J. \& Voytas, D.F. (2010): Targeting DNA double-strand breaks with TAL effector nucleases. Genetics 186: 757-761.

Daboussi, F., Leduc, S., Maréchal, A., Dubois, G., Guyot, V., PerezMichaut, C., Amato, A., Falciatore, A., Juillerat, A., Beurdeley, M., Voytas, D.F., Cavarec, L. \& Duchateau, P. (2014): Genome engineering empowers the diatom Phaeodactylum tricornutum for biotechnology. - Nat. Commun. 5: 3831.

Daboussi, F., Stoddard, T.J. \& Zhang, F. (2015): Engineering Meganuclease for Precise Plant Genome Modification. - In: Zhang, F., Puchta, H. \& Thomson, J.G. (eds.), Advances in New Technology for Targeted Modification of Plant Genomes, pp. 21-38. - Springer New York.

Daboussi, F., Zaslavskiy, M., Poirot, L., Loperfido, M., Gouble, A., Guyot, V., Leduc, S., Galetto, R., Grizot, S., Oficjalska, D., Perez, C., Delacôte, F., Dupuy, A., Chion-Sotinel, I., Le Clerre, D., Lebuhotel, C., Danos, O., Lemaire, F., Oussedik, K., Cédrone, F., Epinat, J.-C., Smith, J., Yáñez-Muñoz, R.J., Dickson, G., Popplewell, L., Koo, T., VandenDriessche, T., Chuah, M.K., Duclert, A., Duchateau, P. \& Pâques, F. (2012): Chromosomal context and epigenetic mechanisms control the efficacy of genome editing by rare-cutting designer endonucleases. - Nucleic Acids Res. 40: 6367-6379. 
Delacôte, F., Perez, C., Guyot, V., Duhamel, M., Rochon, C., Ollivier, N., Macmaster, R., Silva, G.H., Pâques, F., Daboussi, F. \& Duchateau, P. (2013): High frequency targeted mutagenesis using engineered endonucleases and DNA-end processing enzymes. - PloS One 8: e53217.

Deltcheva, E., Chylinski, K., Sharma, C.M., Gonzales, K., Chao, Y., Pirzada, Z.A., Eckert, M.R., Vogel, J. \& Charpentier, E. (2011): CRISPR RNA maturation by trans-encoded small RNA and host factor RNase III. - Nature 471: 602-607.

Doron, L., Segal, N. \& Shapira, M. (2016): Transgene Expression in Microalgae-From Tools to Applications. - Front. Plant Sci. doi: 10.3389/fpls.2016.00505.

Duchateau, P. \& Daboussi, F. (2013): Method for targeted modification of algae genomes. - WO2014076571.

Duchateau, P., Daboussi, F., Sourdive, D. \& Epinat, J. (2014): Modified diatoms for biofuel production. - WO2014207043.

Epinat, J.-C., Arnould, S., Chames, P., Rochaix, P., Desfontaines, D., Puzin, C., Patin, A., Zanghellini, A., Pâques, F. \& Lacroix, E. (2003): A novel engineered meganuclease induces homologous recombination in yeast and mammalian cells. - Nucleic Acids Res. 31: 2952-2962.

Fortunato, A.E., Jaubert, M., Enomoto, G., Bouly, J.-P., Raniello, R., Thaler, M., Malviya, S., Bernardes, J.S., Rappaport, F., Gentili, B., Huysman, M.J.J., Carbone, A., Bowler, C., d'Alcalà, M.R., Ikeuchi, M. \& Falciatore, A. (2016): Diatom Phytochromes Reveal the Existence of Far-Red-Light-Based Sensing in the Ocean. - Plant Cell 28: 616-628.

Gabriel, R., Lombardo, A., Arens, A., Miller, J.C., Genovese, P., Kaeppel, C., Nowrouzi, A., Bartholomae, C.C., Wang, J., Friedman, G., Holmes, M.C., Gregory, P.D., Glimm, H., Schmidt, M., Naldini, L. \& Kalle, C. von. (2011): An unbiased genome-wide analysis of zinc-finger nuclease specificity. - Nat. Biotechnol. 29: 816-823.

Galván, A., González-Ballester, D. \& Fernández, E. (2007): Insertional mutagenesis as a tool to study genes/functions in Chlamydomonas. - Adv. Exp. Med. Biol. 616: 77-89.

Gao, X., Tsang, J.C.H., Gaba, F., Wu, D., Lu, L. \& Liu, P. (2014): Comparison of TALE designer transcription factors and the CRISPR/dCas9 in regulation of gene expression by targeting enhancers. - Nucleic Acids Res. 42: e155.

Gao, H., Wright, D.A., Li, T., Wang, Y., Horken, K., Weeks, D.P., Yang, B. \& Spalding, M.H. (2014): TALE activation of endogenous genes in Chlamydomonas reinhardtii. - Algal Res. 5: 52-60.

Grizot, S., Smith, J., Daboussi, F., Prieto, J., Redondo, P., Merino, N., Villate, M., Thomas, S., Lemaire, L., Montoya, G., Blanco, F.J., Pâques, F. \& Duchateau, P. (2009): Efficient targeting of a SCID gene by an engineered single-chain homing endonuclease. - Nucleic Acids Res. 37: 5405-5419.

Guilinger, J.P., Thompson, D.B. \& Liu, D.R. (2014): Fusion of catalytically inactive Cas9 to FokI nuclease improves the specificity of genome modification. - Nat. Biotechnol. 32: 577-582.

Hopes, A., Nekrasov, V., Kamoun, S. \& Mock, T. (2016): Editing of the urease gene by CRISPR-Cas in the diatom Thalassiosira pseudonana. - Plant Meth 12: 49.

Hsu, P.D., Lander, E.S. \& Zhang, F. (2014): Development and applications of CRISPR-Cas9 for genome engineering. - Cell 157: 1262-1278.

Hu, Q., Sommerfeld, M., Jarvis, E., Ghirardi, M., Posewitz, M., Seibert, M. \& Darzins, A. (2008): Microalgal triacylglycerols as feedstocks for biofuel production: perspectives and advances. Plant J. Cell Mol. Biol. 54: 621-639.
Huesemann, M.H., Hausmann, T.S., Bartha, R., Aksoy, M., Weissman, J.C. \& Benemann, J.R. (2009): Biomass productivities in wild type and pigment mutant of Cyclotella sp. (Diatom). - Appl. Biochem. Biotechnol. 157: 507-526.

Jacquier, A. \& Dujon, B. (1985): An intron-encoded protein is active in a gene conversion process that spreads an intron into a mitochondrial gene. - Cell 41: 383-394.

Jiang, W., Brueggeman, A.J., Horken, K.M., Plucinak, T.M. \& Weeks, D.P. (2014): Successful transient expression of Cas9 and single guide RNA genes in Chlamydomonas reinhardtii. Eukaryot. Cell 13: 1465-1469.

Jinek, M., Chylinski, K., Fonfara, I., Hauer, M., Doudna, J.A. \& Charpentier, E. (2012): A programmable dual-RNA-guided DNA endonuclease in adaptive bacterial immunity. - Science 337: 816-821.

Kilian, O., Benemann, C.S.E., Niyogi, K.K. \& Vick, B. (2011): High-efficiency homologous recombination in the oil-producing alga Nannochloropsis sp. - Proc. Natl. Acad. Sci. U. S. A. 108: 21265-21269.

Kim, Y.G., Cha, J. \& Chandrasegaran, S. (1996): Hybrid restriction enzymes: zinc finger fusions to Fok I cleavage domain. - Proc. Natl. Acad. Sci. U. S. A. 93: 1156-1160.

Kostriken, R., Strathern, J.N., Klar, A.J.S., Hicks, J.B. \& Heffron, F. (1983): A site-specific endonuclease essential for mating-type switching in Saccharomyces cerevisiae. - Cell 35: 167-174.

Lozano, J.-C., Schatt, P., Botebol, H., Vergé, V., Lesuisse, E., Blain, S., Carré, I.A. \& Bouget, F.-Y. (2014): Efficient gene targeting and removal of foreign DNA by homologous recombination in the picoeukaryote Ostreococcus. - Plant J. Cell Mol. Biol. 78: 1073-1083.

Marín-Navarro, J., Manuell, A.L., Wu, J. \& P Mayfield, S. (2007): Chloroplast translation regulation. - Photosynth. Res. 94: 359-374.

Matsuoka, M., Takahama, K. \& Ogawa, T. (2001): Gene replacement in cyanobacteria mediated by a dominant streptomycinsensitive rps12 gene that allows selection of mutants free from drug resistance markers. - Microbiol. Read. Engl. 147: 2077-2087.

Minoda, A., Sakagami, R., Yagisawa, F., Kuroiwa, T. \& Tanaka, K. (2004): Improvement of culture conditions and evidence for nuclear transformation by homologous recombination in a red alga, Cyanidioschyzon merolae 10D. - Plant Cell Physiol. 45: 667-671.

Molnár, A., Schwach, F., Studholme, D.J., Thuenemann, E.C. \& Baulcombe, D.C. (2007): miRNAs control gene expression in the single-cell alga Chlamydomonas reinhardtii. - Nature 447: 1126-1129.

Moscou, M.J. \& Bogdanove, A.J. (2009): A simple cipher governs DNA recognition by TAL effectors. - Science 326: 1501.

Nymark, M., Sharma, A.K., Sparstad, T., Bones, A.M. \& Winge, P. (2016): A CRISPR/Cas9 system adapted for gene editing in marine algae. - Sci. Rep. 6: 24951.

Plecenikova, A., Slaninova, M. \& Riha, K. (2014): Characterization of DNA repair deficient strains of Chlamydomonas reinhardtii generated by insertional mutagenesis. - PloS One 9: e105482.

Plessis, A., Perrin, A., Haber, J.E. \& Dujon, B. (1992): Site-specific recombination determined by I-SceI, a mitochondrial group I intron-encoded endonuclease expressed in the yeast nucleus. Genetics 130: 451-460.

Puchta, H., Dujon, B. \& Hohn, B. (1993): Homologous recombination in plant cells is enhanced by in vivo induction of double 
strand breaks into DNA by a site-specific endonuclease. Nucleic Acids Res. 21: 5034-5040.

Ran, F.A., Hsu, P.D., Lin, C.-Y., Gootenberg, J.S., Konermann, S., Trevino, A.E., Scott, D.A., Inoue, A., Matoba, S., Zhang, Y. \& Zhang, F. (2013): Double nicking by RNA-guided CRISPR Cas9 for enhanced genome editing specificity. - Cell 154: 1380-1389.

Rouet, P., Smih, F. \& Jasin, M. (1994): Expression of a site-specific endonuclease stimulates homologous recombination in mammalian cells. - Proc. Natl. Acad. Sci. U. S. A. 91: 6064-6068.

Schroda, M. (2006): RNA silencing in Chlamydomonas: mechanisms and tools. - Curr. Genet. 49: 69-84.

Schroda, M., Vallon, O., Wollman, F.A. \& Beck, C.F. (1999): A chloroplast-targeted heat shock protein 70 (HSP70) contributes to the photoprotection and repair of photosystem II during and after photoinhibition. - Plant Cell 11: 1165-1178.

Shin, S.-E., Lim, J.-M., Koh, H.G., Kim, E.K., Kang, N.K., Jeon, S., Kwon, S., Shin, W.-S., Lee, B., Hwangbo, K., Kim, J., Ye, S.H., Yun, J.-Y., Seo, H., Oh, H.-M., Kim, K.-J., Kim, J.-S., Jeong, W.-J., Chang, Y.K., \& Jeong, B.-R. (2016): CRISPR/ Cas9-induced knockout and knock-in mutations in Chlamydomonas reinhardtii. - Sci. Rep. 6: 27810.

Silva, G.H., Belfort, M., Wende, W. \& Pingoud, A. (2006): From Monomeric to Homodimeric Endonucleases and Back: Engineering Novel Specificity of LAGLIDADG Enzymes. - J. Mol. Biol. 361: 744-754.

Silva, G., Poirot, L., Galetto, R., Smith, J., Montoya, G., Duchateau, P. \& Pâques, F. (2011): Meganucleases and other tools for targeted genome engineering: perspectives and challenges for gene therapy. - Curr. Gene Ther. 11: 11-27.

Sizova, I., Greiner, A., Awasthi, M., Kateriya, S. \& Hegemann, P. (2013): Nuclear gene targeting in Chlamydomonas using engineered zinc-finger nucleases. - Plant J. Cell Mol. Biol. 73: $873-882$.

Smith, J., Bibikova, M., Whitby, F.G., Reddy, A.R., Chandrasegaran, S. \& Carroll, D. (2000): Requirements for double-strand cleavage by chimeric restriction enzymes with zinc finger DNArecognition domains. - Nucleic Acids Res. 28: 3361-3369.
Smith, J., Grizot, S., Arnould, S., Duclert, A., Epinat, J.-C., Chames, P., Prieto, J., Redondo, P., Blanco, F.J., Bravo, J., Montoya, G., Pâques, F. \& Duchateau, P. (2006): A combinatorial approach to create artificial homing endonucleases cleaving chosen sequences. - Nucleic Acids Res. 34: e149.

Specht, E., Miyake-Stoner, S. \& Mayfield, S. (2010): Micro-algae come of age as a platform for recombinant protein production. - Biotechnol. Lett. 32: 1373-1383.

Takata, M., Sasaki, M.S., Sonoda, E., Morrison, C., Hashimoto, M., Utsumi, H., Yamaguchi-Iwai, Y., Shinohara, A. \& Takeda, S. (1998): Homologous recombination and non-homologous endjoining pathways of DNA double-strand break repair have overlapping roles in the maintenance of chromosomal integrity in vertebrate cells. - EMBO J. 17: 5497-5508.

Tsai, S.Q., Wyvekens, N., Khayter, C., Foden, J.A., Thapar, V., Reyon, D., Goodwin, M.J., Aryee, M.J. \& Joung, J.K. (2014): Dimeric CRISPR RNA-guided FokI nucleases for highly specific genome editing. - Nat. Biotechnol. 32: 569-576.

Vlcek, D., Sevcovicová, A., Sviezená, B., Gálová, E. \& Miadoková, E. (2008): Chlamydomonas reinhardtii: a convenient model system for the study of DNA repair in photoautotrophic eukaryotes. - Curr. Genet. 53: 1-22.

Wang, Q., Lu, Y., Xin, Y., Wei, L., Huang, S. \& Xu, J. (2016): Genome editing of model oleaginous microalgae Nannochloropsis spp. by CRISPR/Cas9. - Plant J. 88: 1071-1081.

Weyman, P.D., Beeri, K., Lefebvre, S.C., Rivera, J., McCarthy, J.K., Heuberger, A.L., Peers, G., Allen, A.E. \& Dupont, C.L. (2014): Inactivation of Phaeodactylum tricornutum urease gene using transcription activator-like effector nuclease-based targeted mutagenesis. - Plant Biotechnol. J. 13: 460-470.

Zhao, T., Wang, W., Bai, X. \& Qi, Y. (2009): Gene silencing by artificial microRNAs in Chlamydomonas. - Plant J. 58: $157-164$.

Manuscript received: 30 August 2016

Accepted: 13 March 2017

Handling editor: Saul Purton 